\title{
Fractal dimension of roughness: Influence of grain size and granular class
}

\author{
Bouzeboudja H*, Melbouci B, Bouzeboudja A
}

\author{
Geomaterials Laboratory, Environment and Development, Mouloud Mammeri University of Tizi-Ouzou, \\ Algeria \\ * Corresponding Author: bouzeboudjah@gmail.com
}

Received: 15-02-2018

Revised: 21-05-2018

Accepted: 25-05-2018

\begin{abstract}
The soil structure can be described as an assembly of elements of various sizes separated by a complex system of cracks and fractures, since the grains of the soil are differentiated by their shape, size and orientation. They are thus differently associated and related, their masses can form complex and irregular configurations which are in general extremely difficult to characterize in exact geometric terms. To understand the mechanical behavior of granular materials, it is then necessary to characterize the grains using the fractal dimension which is a characteristic that indicates the degree of irregularity and fragmentation of the latter.

This experimental work consists in studying the influence of the parameters variation: granular class, grain size and normal stress applied during Casagrande's direct shear tests on the roughness fractal dimension calculated with the method of Box counting. The analysis of the results obtained at the end of a granulometric variation which caused a variation of the fractal dimension of grain roughness. This variation made it possible to analyze the level of fragmentation suffered by the sandstone grains during the various shear tests. This fragmentation produces fines that are the source of variations in the mechanical properties of the sandstone material.
\end{abstract}

Key words: Fractal dimension, crushing, sandstone, direct shear.

\section{Introduction}

The behavior of granulate material is influenced by several parameters such as: granulometry, the size and shape of the grains, their hardness and applied stress, etc... An experimental study is essential for a better understanding of the influence of these parameters (Ovalle, 2013).

Otherwise, to determine the grain size or the grain size variations during the shear test, we will use the notion of fractal dimension which is one of the main features of fractal geometry. Its calculation is a theoretical tool for interpreting problems from the dimensions of the physical quantities involved. It has been used among others in the field of civil engineering. It describes well the irregularity of a grain of the granular material. So, several methods have been developed to calculate the fractal dimension of grains or grain samples. The most used techniques are the new theories of image analysis that are important after photographing the grains (Sezer \& al., 2008). They make it possible to quantify and study the crushing variation of the grains of the different granular classes studied by varying several parameters.

\section{Notion of crushing of grain}

Granular materials may experience breakage or crushing under shear or compression effects. This phenomenon causes their fragmentation under different aspects. The evidence for this phenomenon has been published in several studies of granular materials subjected to mechanical testing (Kim, 1995; Lade \& Yamamura 1996; Mac Dowel \& Bolton 1998; Melbouci 2002 \& 2006a; 2006b; Ovalle 2013; Bouzeboudja \& Melbouci, 2016a; Bouzeboudja \& al., 2016b) 
These different studies have also shown that grain breakage is generally limited to contact points and can extend into the interior of the grain. When the grains are solid, hard and fairly rounded, they can withstand major constraints that require for example the use of heavy machinery or compactors in the construction of high dams earthen and rockfill to meet the requirements of high density. On the other hand, the angular-shaped grains of freshly quarried quarry materials undergo fragmentation due to breakage of the asperities under less severe stresses, and reach higher densities (Ramamurthy, 1969).

Guyon and Troadec (1994) classified grain failure in three ways: abrasion, flaking, and fracture (Figure 1):

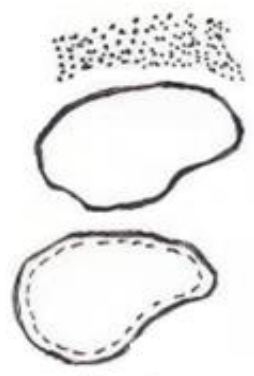

Abrasion

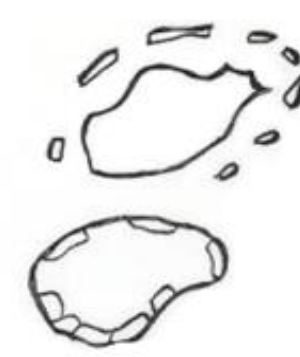

Chipping (or attrition)

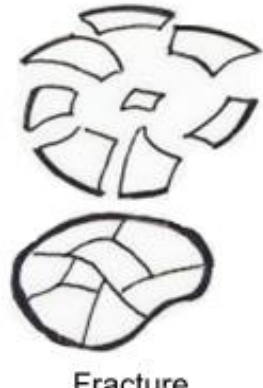

Fracture

Fig 1. Different modes of grain breakdown (Guyon \& Troadec, 1994).

Abrasion: The result is a grain having substantially the same size as the original, but with a production of particles of very small sizes.

Chipping (or attrition): A grain breaks to become smaller, while giving several smaller grains.

Fracture: A grain breaks to give new ones that are substantially equal in size and smaller than the original grain.

\section{Generalities on the fractal dimension and definition of the method used}

The adjective "fractal" was proposed by Mandelbrot in 1975 (Mandelbrot, 1975). It comes from the Latin word "fractus", from the verb "frangere" which means to break, to present irregularities, to fragment at all scales or to split up infinitely.

A fractal object is a geometric structure that repeats, similar to itself, regardless of the scale at which it is observed; then we speak of internal similarity. Mandelbrot defined it as a set that presents irregularities at all its scales of observation, both macroscopically and microscopically.

The fractal dimension is a non-integer number $(0<\mathrm{DF}<3)$ which measures the degree of irregularity or fragmentation of a geometric or natural object or measuring the roughness of a surface and this notion of fractal dimension is applied to scale invariant objects (Fazzalari \& al., 1996).

It is possible to calculate it by various methods, in this work it is the method of counting the boxes that was used for the calculation of the fractal dimension (Tyler \& al., 1992).

\subsection{Method of Box Counting}

This is the most popular calculation method in practice. The fractal dimension calculated by this method gives us an idea of the dimensional distribution of the grains in the granular medium and its fragmentation process (Russel \& al., 1980). In fact, this method consists in dividing the image of a grain into a small square (or box) of the same dimension (meshing system), so the contour of the grain that passes through these boxes is counted, and the same operation is repeated with boxes of decreasing size until reaching the contour close to that of the real grain (Figure 2). 


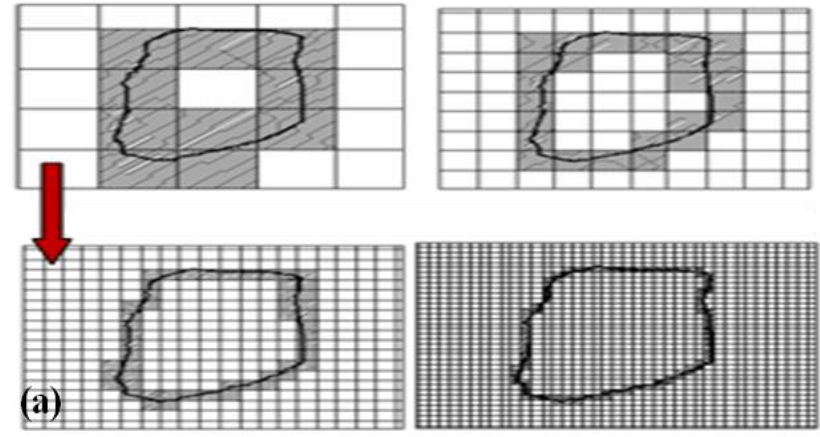

Fig 2. Different steps of meshing of an image of a grain.

This method is based on the principle that the image of the grain will correspond to the number of boxes according to its size and this relation is represented by formula (1):

$\mathrm{N}(\mathrm{X}>\mathrm{x})=\mathrm{kx}^{-\mathrm{DF}}$

$\mathrm{x}$ : size of boxes;

$\mathrm{X}$ : linear dimension of the grains, greater than the dimension $\mathrm{x}$;

$\mathrm{N}(\mathrm{X}>\mathrm{x})$ : number of boxes; $\mathrm{k}$ : constant of proportionality; DF: fractal dimension of roughness (Huang \& Zhan, 2002; Wang \& al., 2006).

By plotting the logarithmic graph of the number of boxes according to the box sizes, the fractal dimension is obtained according to the slope best suited to the line and can be calculated by the equation (2):

$\mathrm{DF}=-\mathrm{m}$

$\mathrm{m}$ : is the exponent of the regression line of the scatter plot.

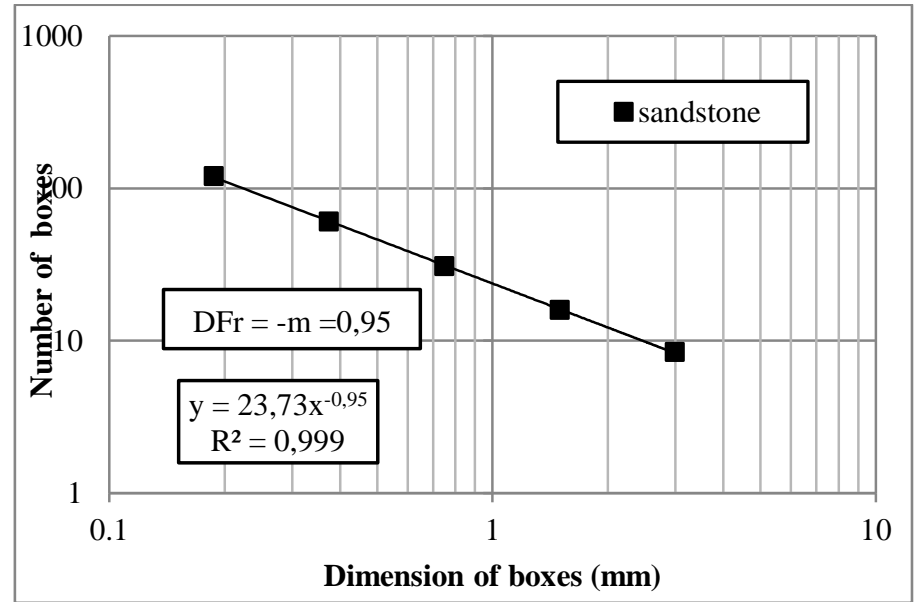

Fig 3. Calculation of the fractal dimension by the Box Counting method of a grain of sandstone.

\section{Material of the study}

The material used in this study is a local material which is sandstone, a sedimentary rock of detrital origin, formed of grains agglomerated by a siliceous, calcareous or ferruginous natural cement, giving a hardness to the whole and with variable cohesion, but generally quite hard and compact, used especially as building and paving material or as sharpening stone. The grains obtained after crushing are characterized by their size and shape

The chemical composition of sandstone is composed mainly of quartz. The material that binds the grains together is generally composed of silica, calcium carbonate or iron oxide. It is this 
binder which gives the material its color, so iron oxide gives red or reddish brown sandstone and the others give white, yellowish or grayish sandstone. The sandstone breakage is characterized by the fracture of the cement but not the grains, which remain whole.

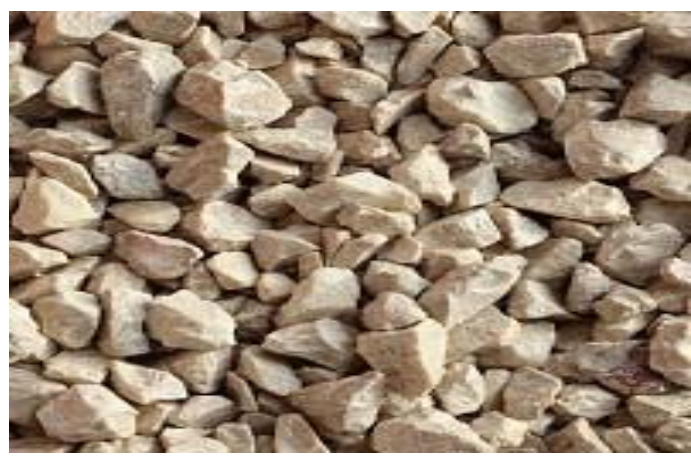

Fig 4. Sandstone studied.

The mineralogical compositions of the sandstone are grouped in Table 1.

Table 1. The chemical compositions of numidian sandstones (Alili \& al., 1999).

\begin{tabular}{|c|c|c|c|c|c|c|c|c|}
\hline $\mathrm{SiO}_{2}(\%)$ & $\mathrm{Fe}_{2} \mathrm{O}_{3}(\%)$ & $\mathrm{Al}_{2} \mathrm{O}_{3}(\%)$ & $\mathrm{CaO}(\%)$ & $\mathrm{MgO}(\%)$ & $\mathrm{MnO}(\%)$ & $\mathrm{Na}_{2} \mathrm{O}(\%)$ & $\mathrm{K}_{2} \mathrm{O}(\%)$ & PAF (\%) \\
\hline \hline $\begin{array}{c}91.57 \text { at } \\
98.64\end{array}$ & $\begin{array}{c}0.10 \text { at } \\
1.8\end{array}$ & $\begin{array}{c}0.04 \text { at } \\
3.60\end{array}$ & $\begin{array}{c}0.10 \text { at } \\
1.05\end{array}$ & $\begin{array}{c}0.02 \text { at } \\
0.21\end{array}$ & $\begin{array}{c}0.01 \text { at } \\
0.05\end{array}$ & 0.05 & $\begin{array}{c}0.01 \text { at } \\
0.51\end{array}$ & $\begin{array}{c}0.29 \text { at } \\
1.35\end{array}$ \\
\hline
\end{tabular}

The physico-mechanical properties of this rock are represented in Tables 2 and 3.

Table 2. The mechanical characteristics of the material studied.

\begin{tabular}{|c|c|c|c|c|}
\hline Characteristics & $\begin{array}{c}\text { Fragmentability } \\
\text { FR }\end{array}$ & Degradability DG & $\begin{array}{c}\text { Micro- } \\
\text { Deval } \\
\text { MDE }\end{array}$ & $\begin{array}{c}\text { Los-Angeles } \\
\text { LA [\%] }\end{array}$ \\
\hline \hline Sandstone & 118 & 1.04 & 91 & 92 \\
\hline
\end{tabular}

Table 3. The physical characteristics of the material used.

\begin{tabular}{|c|c|c|c|c|}
\hline Characteristics & $\begin{array}{c}\text { Optimal } \\
\text { volumetric weight } \\
\text { yopt }\left[\mathrm{kN} / \mathrm{m}^{3}\right]\end{array}$ & $\begin{array}{c}\text { Optimal water } \\
\text { content Wopt } \\
{[\%]}\end{array}$ & $\begin{array}{l}\text { Porosity n } \\
\quad[\%]\end{array}$ & $\begin{array}{c}\text { Volumetric weight of solid } \\
\text { grains } \gamma \mathrm{s}\left[\mathrm{kN} / \mathrm{m}^{3}\right]\end{array}$ \\
\hline Sandstone & 17.6 & 8.33 & 24.5 & 26.3 \\
\hline
\end{tabular}

Sandstone is a fragmentable material with a fragmentation coefficient FR (NF P94-066) greater than 7. The coefficients Micro-Deval MDE (NF P18-572) and Los Angeles LA (NF P18-573) of the sandstone are very high, they are greater than 45; therefore this material is usable neither for the body of roadway nor for the layers of form. The degradability coefficient DG (NF P94-067) of the sandstone is less than 5 , so it is not degradable.

\section{Apparatus and sampling}

The direct shear test makes it possible to quickly characterize the breaking behavior of the granular material. The necessary equipment and procedure are, however, much simpler. The $6 \mathrm{x}$ $6 \mathrm{~cm}$ shear box was used (Figure 5).

The sample to be studied is placed between two half-boxes that can move horizontally relative to each other. A piston makes it possible to exert on the sample a determined normal stress (varying from $100 \mathrm{kPa}$ to $400 \mathrm{kPa}$ ).

The different samples prepared, as well as the direct shear test apparatus and the principle of the procedure followed are used according to French standards (AFNOR, 1994). 

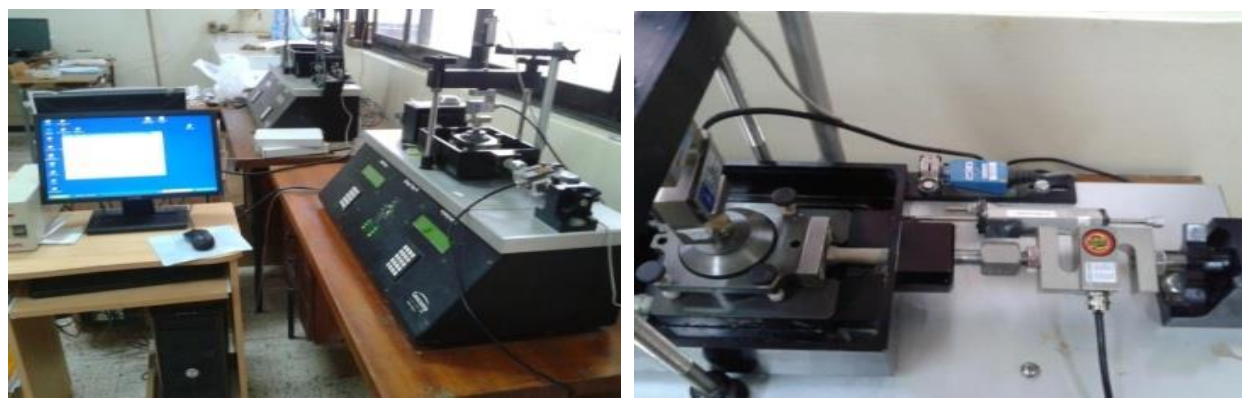

Fig 5. Apparatus for the direct shear test at the Casagrande box.

\section{Sampling}

Three granular classes were studied: $3.15 / 5 \mathrm{~mm}, 5 / 8 \mathrm{~mm}$ and 3.15/8 mm. For each granular class (Figure 6) a series of three samples are made which are subjected to shear tests by varying the normal stress of $100 \mathrm{kPa}, 300 \mathrm{kPa}$ and $400 \mathrm{kPa}$ and for each sample five control grains of each diameter were stained and photographed before and after testing in order to better evaluate their fragmentation during crushing.

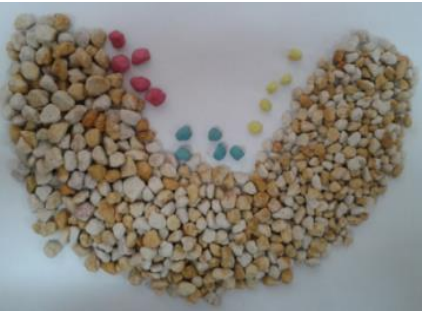

(a)

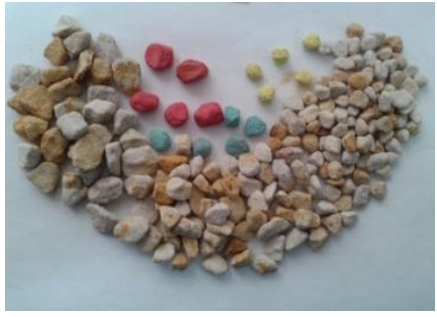

(b)

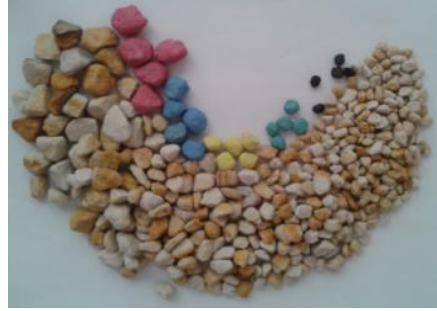

(c)

Fig 6. The granular classes used: $3.15 / 5 \mathrm{~mm}$ (a), 5/8 mm (b) and 3.15/8 mm (c).

\section{Test Carried Out}

The samples reconstituted in the laboratory are prepared in such a way as to be able to study the influence of the granular class and the size of the grains and the particle size distribution on the crushing phenomenon in order to be able to evaluate the fractal dimension of the grains after crushing.

The samples are subjected, in the dry state, to the direct shear tests at the Casagrande box, applying three shear stresses $100 \mathrm{kPa}, 300 \mathrm{kPa}$ and $400 \mathrm{kPa}$ (AFNOR, 1994), these tests show that relative displacements occur between the grains, which result in friction at the points of contact and thus engender their crushing (Figure 7).

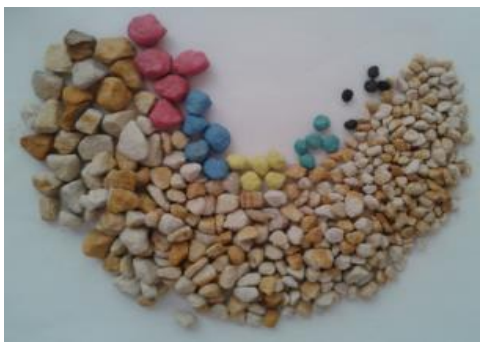

(a)

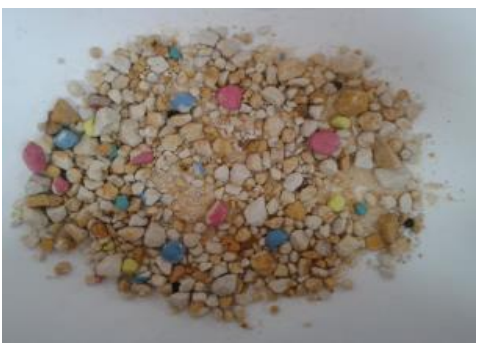

(b)

(a): before the testing and (b): after the testing.

Fig 7. Example of a sample subjected to a stress test of $400 \mathrm{kPa}$. 
The direct shear test is still widely used because of the simplicity of its implementation. It makes it possible to quickly characterize the rupture behavior of the different samples and to study the variation in crushing rate of the grains by comparing the fractal fragmentation dimension values calculated before and after each test with the Box Counting method used.

\section{Presentation and interpretation of test results}

The results obtained are presented in the form of stress-displacement curves. The behavior of granular materials is strongly influenced by the degree of crushing and breaking of grains. Indeed, during the many tests, the samples suffered deformations and ruptures of their grains. The amount of fines produced increases with the increase of the intensity of the normal stress.

We recall that the setting up of the samples is identical for all the tests and that each test has been repeated several times so as to systematically confirm the reproducibility of the results obtained and to better quantify the mechanical characteristics of sandstone.

\subsection{Curves Constraints displacements}

The stress-displacement curves show the evolution of the tangential stress ( $\tau$ [kPa]) as a function of the horizontal displacements $(\Delta \mathrm{L}[\mathrm{mm}])(\tau=\mathrm{f}(\Delta \mathrm{L}))$, which allow to describe the evolution of the shear resistance of the samples according to the studied parameters for sandstone under different normal applied stresses (100, 300 and $400 \mathrm{kPa}$ ) (figure 8 (a)).

During Casagrande box shear tests, sample failure occurs along the plane between the half-boxes where the deformation is imposed.

The shear stresses $(\tau)$ of the samples increase with the increase in the normal stress $(\sigma)$ applied, for the three granular classes (Figure 8 (b)).

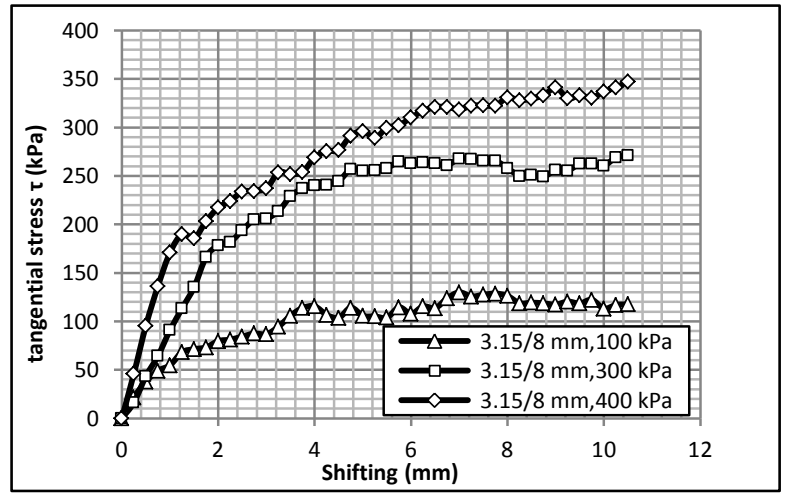

(a)

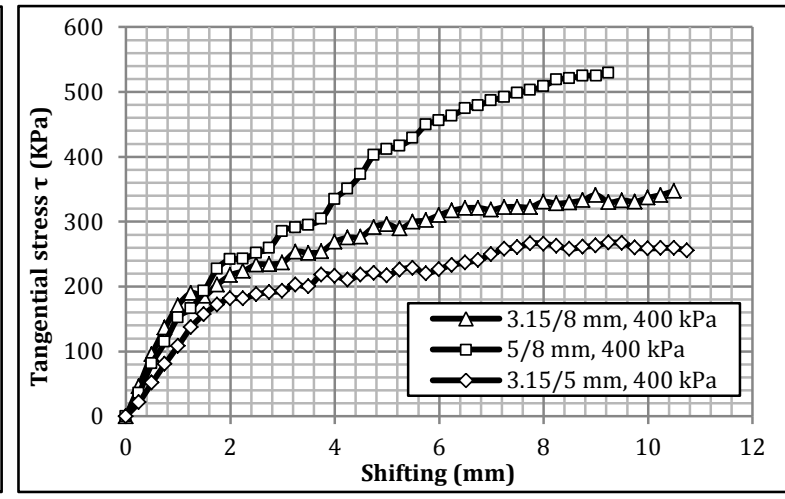

(b)

Fig 8. Evolution of the curves Efforts-displacements.

The stress-displacement curves corresponding to the samples of the sandstone material have a resistance level for very low horizontal displacements. Under high normal stresses (300 and 400 $\mathrm{kPa}$ ), sandstone samples develop new strength after exhausting much of their shear strength. This can be explained by a new restructuring of the grains during their displacement and rotation, which has formed a new, denser matrix with a better reorientation of the grains, thus developing a new resistance. The angles of friction obtained vary according to the granular class (Table 4) and according to the sharp edges of the grains favoring the friction between the grains.

Table 4. Determination of the angle of friction of the different granular classes.

\begin{tabular}{|c|c|}
\hline Granular classes & Sharp edges \\
\hline \hline $3.15 / 8$ & 13.82 \\
\hline $5 / 8$ & 15.37 \\
\hline $3.15 / 5$ & 23.89 \\
\hline
\end{tabular}




\subsection{Particle size distribution}

The particle size of the samples subjected to direct shearing at the Casagrande box is measured before and after each test. The results are shown in the form of granulometric curves, varying the following parameters:

- $\quad$ The normal stress $(100 \mathrm{kPa}, 300 \mathrm{kPa}$ and $400 \mathrm{kPa})$;

- $\quad$ The grain size class $(3.15 / 5 \mathrm{~mm}, 5 / 8 \mathrm{~mm}$ and $3.15 / 8 \mathrm{~mm})$.

Indeed, crushing of grains affects the characteristics of sandstone particularly on the spread of grain size curves. Granulometric analysis before and after each test was performed and compared to the initial grain size curve (Figure 9).

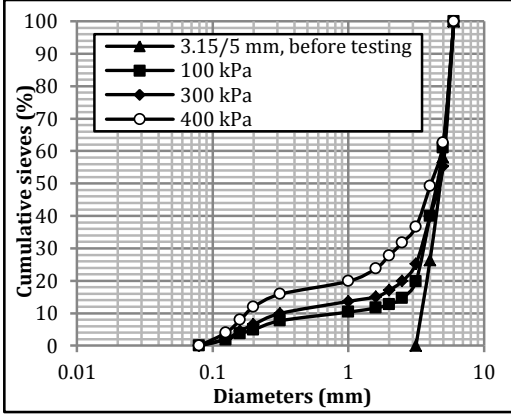

(a)

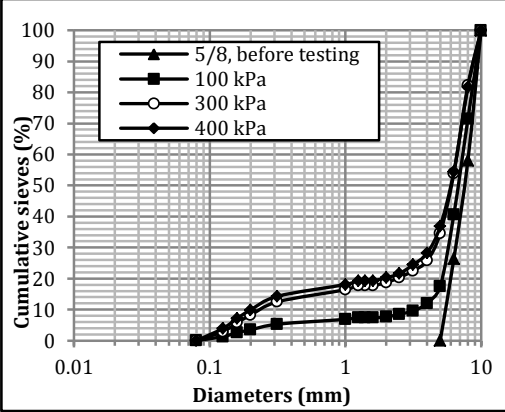

(b)

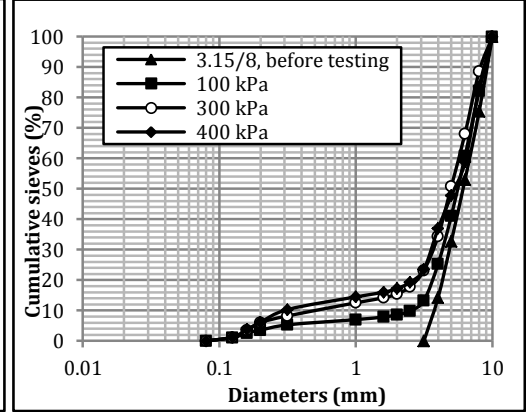

(c)

Fig 9. Granulometric curves before and after shear for the three granular classes used; (a) 3.15/5 mm, (b) $5 / 8 \mathrm{~mm}$ and (c) $3.15 / 8 \mathrm{~mm}$.

Figure 9 shows the evolution of the granulometric spread for the three granular classes used $(3.15 / 5,5 / 8$ and $3.15 / 8 \mathrm{~mm})$ as a function of the increase in the normal stress. The higher the normal stress, the greater the crushing of the grains and the more significant the production of fines. This crushing leads to a reduction in the size of the grains and a modification of the shape and texture of the grains; therefore a modification of the value of the fractal dimension.

Granulometric spreading after the tests is evidence of grain fragmentation. The curves in Figure 9 show that the $5 / 8 \mathrm{~mm}$ size class crushes more than the 3.15 / $8 \mathrm{~mm}$ class, which crushes more than the 3.15 / 5 mm class. The crushing of the grains after the test is shown in Figure 10.

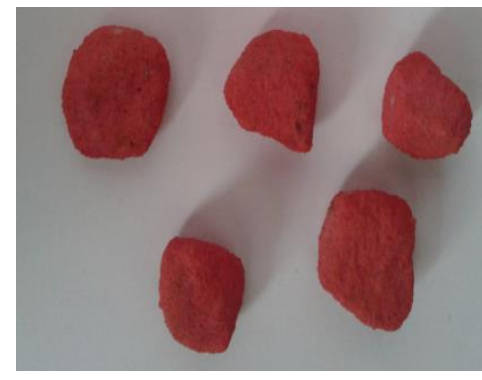

(a)

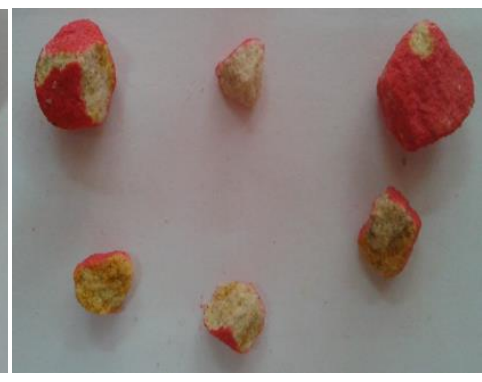

(b)

(a): before the testing and (b): after the testing.

Fig 10. Examples of the sheared grains under a normal stress of $400 \mathrm{kPa}$.

\section{Calculation of the fractal dimension of roughness and interpretation of results}

The fractal dimension of roughness DF was calculated for the different samples studied before and after each run, using the MATLAB R2009b software, to facilitate the calculations, using an implemented program that processes the contour of a grain according to the same principle as the Box Counting method defined above. 
The results of the evolution of the fracture dimension of roughness DF obtained after tests are analyzed, as a function of the applied shear stress, the granular class and the grain size.

\subsection{Study of the influence of normal stress on the evolution of the fractal dimension of roughness}

The following figures show the evolution of the fractal dimension of roughness of the grains of different classes used after the direct shear tests under different applied stresses.

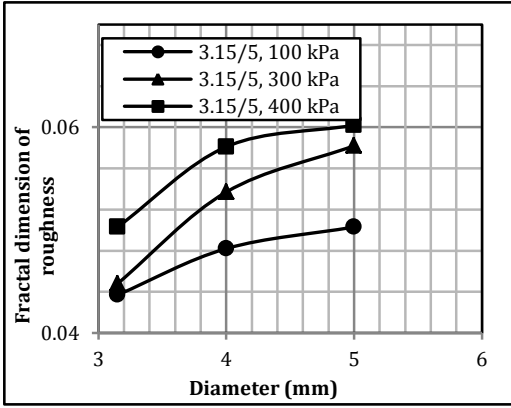

(a)

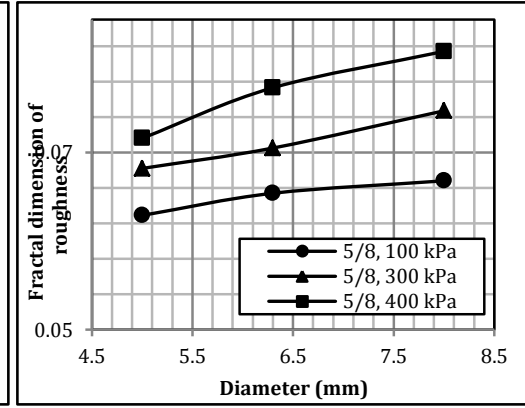

(b)

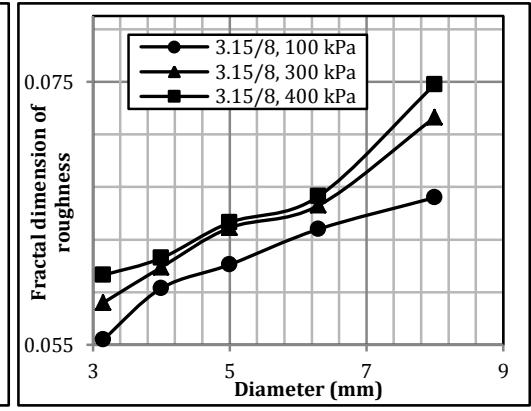

(c)

Fig 11. Influence of the normal stress on the evolution of the fractal dimension of roughness for the three granular classes used, (a) $3.15 / 5 \mathrm{~mm}$, (b) $5 / 8 \mathrm{~mm}$ and (c) $3.15 / 8 \mathrm{~mm}$.

Figure 11 shows that the variation of the fractal dimension of roughness increases with the increase of the applied normal stress. So the more the stress increases, the more the crushing rate increases, as the grains change shape and become more irregular and rough.

The production of fines during the tests is greater in the case of grains of large diameters ( 8 and $6.3 \mathrm{~mm}$ ) than in the case of grains of small diameters ( 4 and $3.15 \mathrm{~mm}$ ). The $8 \mathrm{~mm}$ grains suffered a greater crushing, due to the rupture of angularities by abrasion; on the other hand for the small grains 3.15 and $4 \mathrm{~mm}$, it is a rupture by peeling which caused the increase of the roughness of the grains. This result is explained by the fact that the smaller grains are stronger than the larger ones. Indeed, the more the size increases, the more the probability of presence of the zones of weakness (or cracking) in the grain increases.

\subsection{Study of the influence of the granular class on the evolution of the fractal dimension of roughness}

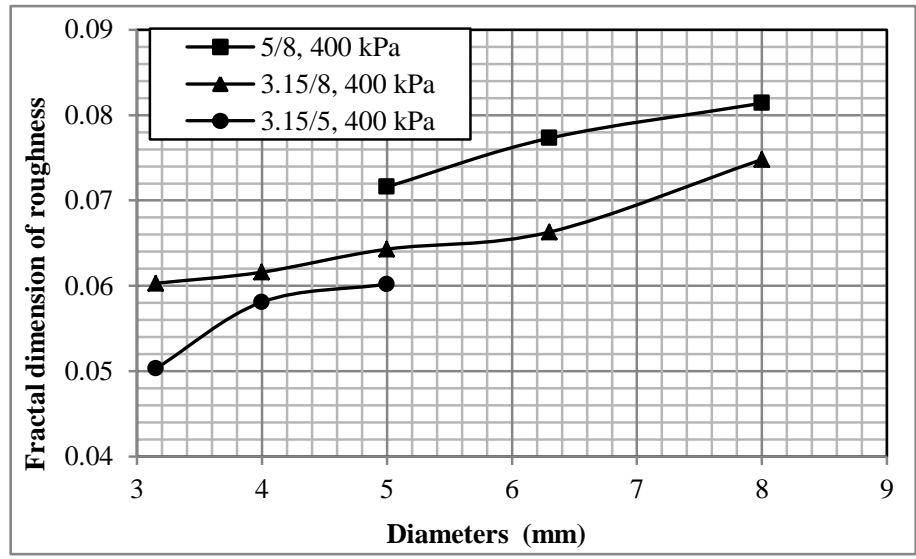

Fig 12. Evolution of the fractal dimension DF as a function of the size of the grains.

The evolution curves of the fractal dimension of roughness DF of the various granular classes (Figure 12) show that: 
The highest fractal dimension deviation after crushing is obtained for the normal stress of 400 $\mathrm{kPa}$ and for the class $5 / 8 \mathrm{~mm}$. This can be explained by the presence of angularities or cracks in the coarse grains which may possibly favor their crushing more than the small grains. This crushing causes the increase of the roughness of their surface parts, thus increasing the fractal dimension of roughness.

The smallest fractal dimension after crushing is that of class $3.15 / 5 \mathrm{~mm}$. This can be explained by the fact that small grains crash less so a lesser change occurs in their shape. This dimension DF calculated increases with the increase of the size of the grains (diameter of the grains) of the sandstone and this regardless of the granular class.

\section{Conclusions}

The box counting method gives the fractal dimension of roughness DF which indicates the degree of roughness with respect to a given grain sample.

The results obtained after the direct shear tests showed that all the samples studied underwent appreciable crushing under maximum normal stress of $400 \mathrm{kPa}$, particularly for the granular class $(5 / 8)$.

The fractal dimension determined by the box-counting method clearly describes the irregularity of the grains of the granular material. This dimension increases after the shear tests. The greater the fragmentation, the greater the difference in the fractal dimension of roughness and the finer the production.

These results lead to the conclusion that:

Micro cracks propagate when the grains are subjected to high loading, which gives us an important cause of grain breakage. Indeed, the larger the size of the grain, the greater the likelihood of occurrence of areas of weakness.

The phenomenon of crushing of the grains revealed the evolution of the fractal dimension. The grains may undergo crushing during shear, the extent of which depends on shear strength, roughness size, hardness, shape and grain surface.

\section{References}

AFNOR (1994). Essai de cisaillement rectiligne à la boîte, Partie1: Cisaillement direct. XPP 94-071-1, p16.

Alili, H., \& Amokrane, D. (1999). Comportement Mécanique des Grés. Mémoire d'Ingénieur Université Mouloud Mammeri, Tizi-Ouzou (UMMTO).

Bolton, M.D \& Mc Dowell, G.R. (1998). On the Micromechanics of Crushable Aggregates. Géotechnique 48, $\mathrm{N}^{\circ} 5$.

Bouzeboudja, A., \& Melbouci B. (2016a). Study of the evolution of the fractal dimension of a granular material's grains during mechanical tests. Bulletin of Engineering Geology and the environment, Volume 75, Issue 2,pp 821-839.

Bouzeboudja, A. , Melbouci, B., \& Bouzeboudja, H. (2016b). Characterization of aggregates fragmentation using the calculation of fractal dimension" 16th International Conference on New Trends in Fatigue and Fracture (NT2F16), May 24-27, 2016, Dubrovnik, Croatia, ISBN 978-953-7738-39-6, pp. 211-213.

Fazzalari, N.L., \& Parkinson, I.H. (1996). Fractal dimension and architecture of trabecular bone. Journal of Pathology. Vol 178, pp.100-105.

Guyon, E., \& Troadec, J.P. (1994). Du Sac de Billes au tas de Sables. Editions Odile JACOB Sciences, Paris.

Huang, G.H., \& Zhan, W.H. (2002). Fractal property of soil particle size distribution and its application. Acte Pedologica Sinica, 39, pp. 490-497. 
Kim, M.S. (1995). Etude Expérimentale Du Comportement Mécanique Des Matériaux granulaires sous Fortes contraintes. Thèse de doctorat de l'école centrale de paris.

Lade, P.V., Yamamuro, J.A., \& al. (1996). Significance of particule crushing in granular materials. Journal de la technologie géotechnique, vol.122, $\mathrm{N}^{\circ} 4$, pp. 3109-3116.

Mandelbrot, B. (1975). Les objets fractals : forme, hasard et dimension. Editions Flammarion, Paris.

Melbouci, B., \& Hannachi, N. E. (Septembre, 2002). Etude de l'écrasement des grains de pegmatite à l'essai oedométrique. Annales de BTP, $\mathrm{N}^{\circ} 4$., France.

Melbouci, B. (2006a). Etude du phénomène d'écrasement des grains de schiste au compactage. Revue Française de Géotechnique, $\mathrm{N}^{\circ} 117,4^{\circ}$ trimestre 2006.

Melbouci, B., \& Roth J.C. (Juin., 2006b). Etude du comportement des matériaux concassés à l'écrasement. Annales de BTP, $\mathrm{N}^{\circ} 3$., France.

Ovalle, C. (2013). Contribution a l'étude de la rupture des grains dans les matériaux granulaires. MECHANICS OF MATERIALS. Ecole Centrale de Nantes (ECN), French.

Ramamurthy, T. (1969). Crushing Phenomena in Granular Soils. Journal of the Indian National Society of Soil Mechanics and Foundation Eng. Vol. 8.

Russel, D., Hanson, J., \& OTT, E. (1980). Dimension of strange attractors. Physical review Letters 45, 11751178.

Sezer, A., Altun, S., \& Erdogan, D. (2008). Correlation between CBR Strength and fractal Dimensions of Sands. 12eme Conference international de (IACMAG), 1-6 October, Goa Indian.

Tyler, S.W., \& Wheatcraft, S.W. (1992). Fractal scaling of soil particle-size distributions: analysis and limitations. Soil Sei. Soc. Am. J. 56: 362-369.

Wang, X., LI, M.H., Lui, S., \& Lui, G. (2006). Fractal characteristics of soils under different land-usepatterns in the arid and semiarid regions of the Tibetan plateau. China, Geoderma, 134 (1-2), pp. 56-61. 